\title{
ANEURYSM OF ABDOMINAL AORTA TREATED BY OPERATION.
}

\author{
By J. LUMSDEN, M.D., \\ Physician to Mercer's Hospital, Dablin ;
}

AND
W. I. DE C. WHEELER, M.D., F.R.C.S., Surgeon to Mercer's Hospital, Dublin.

[Read in the Section of Medicine, December 16, 1910.]

The patient, G. T., was aged thirty-eight. He was a brewery labourer. The family history was unimportant. His father died in the Richmond Asylum, aged sixtyfour. As a boy he was quite healthy, and had no serious illness. He was in the army for sixteen years. He served in India for seven years, in South Africa for four years, and was through the war, only being off duty for ten days owing to an attack of dysentery. He entered the brewery service seven years ago, for the past four of which he was employed in the cooperage department piling empty barrels, a class of work causing a good deal of strain of a more or less heavy order. Sixteen years ago he contracted syphilis, and was treated by the R.A.M.C. Officers. He is married, and has three healthy children; his wife had one miscarriage. His general health was excellent until last January, when he began to complain of dyspepsia and constipation, which came on periodically, but generally reacted readily to treatment.

In June he came to see me at my dispensary, and was then suffering from nausea, occasional vomiting, flatulence, and discomfort, coming on an hour or so after meals, and often relieved by taking food. Couch examination revealed a somewhat dilated stomach and perhaps some undue pulsa- 
tion in epigastrium, but at this time I did not suspect the presence of an aneurysm, but marked the case as a possible gastric or duodenal ulcer. An alkaline bismuth mixture appeared to relieve the symptoms.

He worked up to September, when, for the first time, a swelling was discovered by my assistant, Dr. Day, in the epigastrium. I admitted him to Mercer's Hospital at once. Condition then was noted as follows:-

A spare man, about ten stone in weight, fairly well nourished. He has been losing weight somewhat. Heart sounds normal but for slightly accentuated aortic second sound, apex normally situated, radial pulse 60 regular, perhaps a trifle hard. Blood pressure of radial taken with Cruise's sphygmometer 110 millimetres of mercury. Sphygmographic tracing showed little difference from normal curve. Femoral pulses palpable and of fair volume. On inspection of abdomen a well-marked pulsation was visible in epigastrium, more marked to left of middle line. On palpation a distinct tumour was felt, extending upwards under the left costal arch. It was circumscribed, tense with forcible impulse of a distinctly expansile character. It did not descend with inspiration; the percussion note over it was dull. A loud bruit, systolic in time, was to be heard, not over but below the lump, and this could be traced down the aorta and into both femoral arteries.

The patient complained of no pain in the back or elsewhere, and while in bed appeared comfortable and with few complaints, except slight gastric discomfort at times. An $\mathrm{X}$-ray photograph was taken, but owing to the situation of the growth little shadow was shown or assistance given as to the extent of the growth.

The diagnosis of saccular aneurysm of aorta probably about origin of cœliac axis appeared to be the only satisfactory explanation. He was kept absolutely at rest in recumbent position, placed on a modified Tufnell's diet, and given a course of potassium iodide, the latter in daily doses of 30 grains, increased later to 90 grains, and a morning dose of sodium sulphate. I cannot say that any improvement came about; if anything the aneurysm became larger, extending downwards to a lower level, and the impulse grew more forcible and tumultuous. 
Under these circumstances, and as little could be hoped for from medical treatment, and certain death only a matter of time, I asked my colleague, Mr. Wheeler, to see the case with me, and after much discussion I transferred the man to the surgical ward under his care, and he will now inform you of the operation performed.

The success so far obtained since the operation, which took place over six weeks ago, is, I think, as satisfactory as one could reasonably expect. The tumour is still readily seen and felt, but the impulse is not so forcible, and even discounting the inflammatory thickening underlying the cicatrix the aneurysm feels harder and undoubtedly somewhat smaller in size I believe. He is at present taking 20 grains of potassium iodide thrice daily, and his fluid intake reduced to a minimum compatible with comfort.

Mr. W. I. DE C. WheELER described the evolution of the surgery of abdominal aneurysm. The case exhibited resembled the vast majority in being a male, having a specific history, and having the aneurysm springing from the region of the cœliac axis. The operation took place seven weeks ago, and 150 inches of gilded wire in the form of a cage by the method of Colt and D'Arcy Power was introduced into the sac. For the first few days the aneurysmal pulsation was more tumultuous than before the operation, but since then there has been a distinct diminution of pulsation and hardening of the tumour.

The operation was performed with the strictest aseptic precautions, and was facilitated by placing a sand bag under the patient's back and tilting the table so that the pelvis and feet were low and the intestines fell away into the pelvis (Mayo Robson's gall-bladder position). There was no hæmorrhage.

Statistics demonstrated a small percentage of cures in the cases operated upon, but the prognosis was hopeless when 
operation was not possible, Osler and other authorities never having seen a cure under medical treatment. Post-mortem examinations of cases which died even a short time after operation revealed a firm laminated clot in which the wire was imbedded.

Electrolysis was not employed in this case, as there is not sufficient experimental evidence of its value in inducing coagulation. The risk of sepsis is increased owing to the prolongation of the operation and the difficulty of sterilisation of insulated instruments and electrical apparatus.

Colt's instrument makes the operation very easy and very safe.

In conclusion, Mr. Wheeler referred to the differential diagnosis and the causes of failure in many of the early operations. His was the first patient exhibited in Dublin after operation for abdominal aneurysm.

Dr. Walter Smith said the case was, as far as he knew, the first demonstrated in Dublin. The main subject for congratulation was that the patient had survived, though living after an operation was no proof that it prolonged life, and patients had lived with an untreated aneurysm. He hoped none of his friends would ever introduce wire into his aorta, as he considered the operation both unpathological and unscientific. The only chance of cure was by nature laying down tough, laminated fibrin. A foreign body might induce embolism, and was very dangerous.

Dr. Parsons recalled a case in which the symptoms began in 1896, and the patient did laborious work until within two years of his death in 1906. He thought the chances of repeating such a successful result as Mr. Wheeler's were very small.

Dr. Kirkpatrick said he believed the patient to be in a much safer position than before the operation. He did not see why, because clotting was induced by a foreign body, it should be a soft clot and remain so. He thought the clot, if it completely filled the aneurysm, would become hard. The results had shown firm clotting, with no liability to the production of emboli. Operative technique had greatly improved, and there was good reason to hope that such 
cases could be operated on without sepsis. If the surgeon could make sepsis a rarity, instead of a common occurrence, the operation would probably be attended with a very much smaller mortality, and possibly with a very much greater number of cures.

Dr. H. Stокеs inquired as to the collateral circulation set up.

DR. LUMSDEN, in reply, said that medical treatment of aneurysm in the past had been distinctly unsatisfactory. He had himself had four cases under his care-three men and one woman. The woman died suddenly six months after diagnosis, and no cause of death was discovered. One of the men died suddenly three months after diagnosis. There was no post-mortem, but he believed the aneurysm had burst. The third case had been operated on six years ago by Mr. Maunsell, who introduced twenty-four feet of wire, and performed electrolysis, but the aneurysm perforated through to the stomach, and the patient died about the fifth day. The post-mortem gave a beautiful picture of a laminated clot, showing the process of healing going on. The present patient had been getting worse before the surgeon took him over, and now he was much better, and he thought there was fair hope for the future.

Mr. WHEELER, in reply, said that death was the result in nearly every case without operative treatment. The postmortem, in cases where operation had been done, showed not a soft clot, but a laminated clot, sometimes consolidated altogether, so that he did not see how the operation could be regarded as unscientific. Collateral circulation was well established, though by what means he did not know. No cases published, without operation, showed any cures; while there had been cures in every series with operation, so that he thought the operation was undoubtedly justifiable. 